\title{
How to Construct a Second-Order Achromat with a 90 Phase Advance
}

\author{
T. Kobilarcik
}

June 29, 2000

\begin{abstract}
The author shows how to construct a second order achromatic $\left(T_{i j 6}=\right.$ $0, i, j \in\{1,2\})$ beamline with a total phase advance of $450^{\circ}\left(360^{\circ}+90^{\circ}\right)$.
\end{abstract}

\section{Overview}

The goal is to construct a $90^{\circ}$ cell which is achromatic to second order. One possible way to do this is to construct a $360^{\circ}$ sector followed by a $90^{\circ}$ cell; put dipoles and sextupoles in the $360^{\circ}$ sector; and "throw" the aberrations into the $90^{\circ}$ cell such that the final transformation is achromatic.

We will express the aberrations in the $360^{\circ}$ sector in terms of the $90^{\circ}$ cell and determine whether any combination of sextupoles gives the correct cancellation.

\section{Formalism}

The first-order transfer matrix of a $360^{\circ}$ sector is the unit matrix

$$
\mathbf{R}\left(360^{\circ}\right)=\left(\begin{array}{cccccc}
1 & 0 & 0 & 0 & 0 & 0 \\
0 & 1 & 0 & 0 & 0 & 0 \\
0 & 0 & 1 & 0 & 0 & 0 \\
0 & 0 & 0 & 1 & 0 & 0 \\
0 & 0 & 0 & 0 & 1 & 0 \\
0 & 0 & 0 & 0 & 0 & 1
\end{array}\right)
$$

and that of the last $90^{\circ}$ cell, corresponding to the cell beginning and ending midway between two quadrupoles, is

$$
\mathbf{R}\left(90^{\circ}\right)=\left(\begin{array}{cccccc}
-\sqrt{2} & 3 L / 4 & 0 & 0 & 0 & 0 \\
-4 / L & \sqrt{2} & 0 & 0 & 0 & 0 \\
0 & 0 & \sqrt{2} & 3 L / 4 & 0 & 0 \\
0 & 0 & -4 / L & -\sqrt{2} & 0 & 0 \\
0 & 0 & 0 & 0 & 1 & 0 \\
0 & 0 & 0 & 0 & 0 & 1
\end{array}\right)
$$


The second order elements may be calculated using

$$
T\left(450^{\circ}\right)_{i j k}=\sum_{l} R\left(90^{\circ}\right)_{i l} T\left(360^{\circ}\right)_{l j k}+\sum_{l, m} T\left(90^{\circ}\right)_{i l m} R\left(360^{\circ}\right)_{l j} R\left(360^{\circ}\right)_{m k}
$$

Limiting ourselves to the bend-plane, and recalling from eq. (1) that $R_{i j}\left(360^{\circ}\right)=$ 0 for $j \neq i$, we can calculate the chromatic aberrations at the end of the beamline:

$$
\begin{aligned}
& T\left(450^{\circ}\right)_{116}=R\left(90^{\circ}\right)_{11} T\left(360^{\circ}\right)_{116}+R\left(90^{\circ}\right)_{12} T\left(360^{\circ}\right)_{216} \\
&+ T\left(90^{\circ}\right)_{116} R\left(360^{\circ}\right)_{11} R\left(360^{\circ}\right)_{66} \\
& T\left(450^{\circ}\right)_{126}=R\left(90^{\circ}\right)_{11} T\left(360^{\circ}\right)_{126}+R\left(90^{\circ}\right)_{12} T\left(360^{\circ}\right)_{226}+T\left(90^{\circ}\right)_{126} R\left(360^{\circ}\right)_{22} R\left(360^{\circ}\right)_{66} \\
& T\left(450^{\circ}\right)_{216}=R\left(90^{\circ}\right)_{21} T\left(360^{\circ}\right)_{116}+R\left(90^{\circ}\right)_{22} T\left(360^{\circ}\right)_{216} \\
&+
\end{aligned}
$$

We want $\mathbf{T}\left(450^{\circ}\right)=0$, so refer to eq. (1), note that $R_{i i}\left(360^{\circ}\right)=1$, and solve for $\mathbf{T}\left(90^{\circ}\right)$ :

$$
\begin{aligned}
-T\left(90^{\circ}\right)_{116} & =T\left(360^{\circ}\right)_{116} R\left(90^{\circ}\right)_{11}+T\left(360^{\circ}\right)_{216} R\left(90^{\circ}\right)_{12} \\
-T\left(90^{\circ}\right)_{126} & =T\left(360^{\circ}\right)_{126} R\left(90^{\circ}\right)_{11}+T\left(360^{\circ}\right)_{226} R\left(90^{\circ}\right)_{12} \\
-T\left(90^{\circ}\right)_{216} & =T\left(360^{\circ}\right)_{116} R\left(90^{\circ}\right)_{21}+T\left(360^{\circ}\right)_{216} R\left(90^{\circ}\right)_{22} \\
-T\left(90^{\circ}\right)_{226} & =T\left(360^{\circ}\right)_{126} R\left(90^{\circ}\right)_{21}+T\left(360^{\circ}\right)_{226} R\left(90^{\circ}\right)_{22}
\end{aligned}
$$

Now, note that $R\left(90^{\circ}\right)_{11}=-R\left(90^{\circ}\right)_{22}$ and $T\left(360^{\circ}\right)_{116}=-T\left(360^{\circ}\right)_{226}{ }^{1}$, and write eqs. (2-5) as the system:

$$
\left(\begin{array}{cccc}
R_{11} & R_{12} & 0 & 0 \\
R_{21} & -R_{11} & 0 & 0 \\
0 & 0 & R_{11} & R_{12} \\
0 & 0 & R_{21} & -R_{11}
\end{array}\right)_{90^{\circ}}\left(\begin{array}{c}
T_{116} \\
T_{216} \\
T_{126} \\
-T_{116}
\end{array}\right)_{360^{\circ}}=\left(\begin{array}{c}
-T_{116} \\
-T_{216} \\
-T_{126} \\
-T_{116}
\end{array}\right)_{90^{\circ}}
$$

We now solve for $\mathbf{T}\left(360^{\circ}\right)$ :

$$
\left(\begin{array}{c}
T_{116} \\
T_{216} \\
T_{126} \\
-T_{116}
\end{array}\right)_{360^{\circ}}=\left(\begin{array}{cccc}
-R_{11} & -R_{12} & 0 & 0 \\
-R_{21} & +R_{11} & 0 & 0 \\
0 & 0 & -R_{11} & -R_{12} \\
0 & 0 & -R_{21} & +R_{11}
\end{array}\right)_{90^{\circ}}\left(\begin{array}{l}
-T_{116} \\
-T_{216} \\
-T_{126} \\
-T_{116}
\end{array}\right)_{90^{\circ}}
$$

Eq. (6) expresses the aberrations needed in the $360^{\circ}$ sector such that, when transported through the $90^{\circ}$ cell, the final aberrations are all zero. We now need to calculate the individual terms.

${ }^{1}$ Refer to Appendix B 


\subsection{Individual Terms}

The general procedure for calculating the second order terms will be to differentiate, with respect to the fractional change in momentum $\left(\delta=\frac{\Delta p}{p}\right)$, the appropriate term in the first order transfer matrix for a lattice and then substitute terms particular to a $90^{\circ}$ ) cell. ${ }^{2}$

The equation for a lattice of $n$ identical cells is:

$$
\mathbf{R}=\left(\begin{array}{cc}
\cos n \mu+\alpha \sin n \mu & \beta \sin n \mu \\
-\gamma \sin n \mu & \cos n \mu-\alpha \sin n \mu
\end{array}\right)
$$

where $\mu$ is the phase advance per cell. For a $90^{\circ}$ cell, beginning and ending between two magnets, the following relations will be useful:

$$
\begin{aligned}
\beta & =\frac{L}{\sin \mu}\left(1-\frac{1}{2} \sin ^{2}(\mu / 2)\right) \\
\alpha & =\frac{-2 \sin (\mu / 2)}{\sin \mu} \\
\gamma & =\frac{8}{L} \sin ^{2}(\mu / 2) \\
\mu^{\prime} & =-2 \tan \mu / 2
\end{aligned}
$$

As an example, let us calculate $T\left(90^{\circ}\right)_{216}$ :

$$
\begin{aligned}
T\left(90^{\circ}\right)_{216} & =\left(x^{\prime} \mid x_{0} \delta\right) \\
& =\frac{\partial c^{\prime}}{\partial \delta} \\
& =\frac{\partial}{\partial \delta}[-\gamma \sin (n \mu)] \\
& =-\left(\gamma^{\prime} \sin (n \mu)+\gamma n \mu^{\prime} \cos (n \mu)\right) \\
& =-\gamma^{\prime}
\end{aligned}
$$

where the prime indicates differentiation with respect to $\delta$, and we have made use of the fact than $n \mu=90^{\circ}$. Using eq. (9), the derivative of $\gamma$ with respect to $\delta$ is

$$
\begin{aligned}
\gamma^{\prime} & =\frac{\partial}{\partial \delta}\left[\frac{8}{L} \sin ^{2}(\mu / 2)\right] \\
& =\frac{8}{L} \mu^{\prime} \sin (\mu / 2) \cos (\mu / 2) \\
& =-\frac{16}{L} \sin (\mu / 2) \cos (\mu / 2) \tan (\mu / 2)
\end{aligned}
$$

${ }^{2}$ This follows the method used in chapter 10.2 of

D. C. Carey, The Optics of Charged Particle Beams, Accelerators and Storage Rings, Vol.6, Harwood Academic Publishers, New York (1987). 
where eq. (10) has been used in the last line. Substituting eq. (12) into eq. (11) gives our final answer:

$$
\begin{aligned}
T\left(90^{\circ}\right)_{216} & =\frac{16}{L} \sin (\mu / 2) \cos (\mu / 2) \tan (\mu / 2) \\
& =\frac{8}{L}
\end{aligned}
$$

The remaining terms of the $90^{\circ}$ cell are calculated in Appendix A. In general, for a $90^{\circ}$ cell, the length of the cell, $L$, is related to the focal length of the quadrupoles, $f$, by $L=2 \sqrt{2} f$, it makes sense to express the aberrations in terms of $L$.

The terms for a $360^{\circ}$ sector are calculated in Appendix B. In this case, the aberrations are expressed in terms of the number of cells, $n$, the Twiss parameters at the end of the first cell, $\alpha, \beta, \gamma$, and the change in phase advance with respect to fractional momentum deviation, $\mu^{\prime}$.

For ease of reference, all first and second order terms for the $90^{\circ}$ sector and $360^{\circ}$ cell are summarized in Table 1.

\subsection{Solution}

We can calculate the ratios of the $T_{i j 6}$ to the $T_{116}$ aberration:

$$
\begin{aligned}
& \frac{T\left(360^{\circ}\right)_{126}}{T\left(360^{\circ}\right)_{116}}=\frac{\beta}{\alpha} \\
& \frac{T\left(360^{\circ}\right)_{216}}{T\left(360^{\circ}\right)_{116}}=\frac{-\gamma}{\alpha} \\
& \frac{T\left(360^{\circ}\right)_{226}}{T\left(360^{\circ}\right)_{116}}=-1
\end{aligned}
$$

We can also substitute the expressions from Table 1 into eq. (6) to calculate the values of $360^{\circ}$ sector aberrations needed to zero the aberrations at the end

\begin{tabular}{cc|cc}
$R\left(90^{\circ}\right)_{11}$ & $-\sqrt{2}$ & $T\left(90^{\circ}\right)_{116}$ & $2\left(1+\frac{\sqrt{2}}{2}\right)$ \\
$R\left(90^{\circ}\right)_{12}$ & $3 L / 4$ & $T\left(90^{\circ}\right)_{126}$ & $L / 2$ \\
$R\left(90^{\circ}\right)_{21}$ & $-4 / L$ & $T\left(90^{\circ}\right)_{216}$ & $8 / L$ \\
$R\left(90^{\circ}\right)_{22}$ & $+\sqrt{2}$ & $T\left(90^{\circ}\right)_{226}$ & $2\left(1-\frac{\sqrt{2}}{2}\right)$ \\
\hline \hline$R\left(360^{\circ}\right)_{11}$ & 1 & $T\left(360^{\circ}\right)_{116}$ & $\alpha n \mu^{\prime}$ \\
$R\left(360^{\circ}\right)_{12}$ & 0 & $T\left(360^{\circ}\right)_{126}$ & $\beta n \mu^{\prime}$ \\
$R\left(360^{\circ}\right)_{21}$ & 0 & $T\left(360^{\circ}\right)_{216}$ & $-\gamma n \mu^{\prime}$ \\
$R\left(360^{\circ}\right)_{22}$ & 1 & $T\left(360^{\circ}\right)_{226}$ & $-\alpha n \mu^{\prime}$
\end{tabular}

Table 1: First and second order terms for a single $90^{\circ}$ cell and a $360^{\circ}$ sector. 


\begin{tabular}{ccc} 
Ratio & Needed & Actual \\
\hline$T_{126} / T_{116}$ & - & - \\
$T_{216} / T_{116}$ & - & + \\
$T_{226} / T_{116}$ & - & -
\end{tabular}

Table 2: Signs of the ratios of aberrations. "Actual" refers to ratio without sextupoles. "Needed" refers to the ratio needed in order to make all aberrations in the beamline zero.

of the $450^{\circ}$ beamline.

$$
\begin{aligned}
T\left(360^{\circ}\right)_{116} & =R\left(90^{\circ}\right)_{11} T\left(90^{\circ}\right)_{116}+R\left(90^{\circ}\right)_{12} T\left(90^{\circ}\right)_{216} \\
& =2(2-\sqrt{2})= \\
T\left(360^{\circ}\right)_{216} & =R\left(90^{\circ}\right)_{21} T\left(90^{\circ}\right)_{116}-R\left(90^{\circ}\right)_{11} T\left(90^{\circ}\right)_{216} \\
& =-4\left(\frac{2-\sqrt{2}}{L}\right) \\
T\left(360^{\circ}\right)_{126} & =R\left(90^{\circ}\right)_{11} T\left(90^{\circ}\right)_{126}+R\left(90^{\circ}\right)_{12} T\left(90^{\circ}\right)_{226} \\
& =-\frac{L}{2}\left(\frac{5 \sqrt{2}}{2}-3\right) \\
T\left(360^{\circ}\right)_{226} & =R\left(90^{\circ}\right)_{21} T\left(90^{\circ}\right)_{126}-R\left(90^{\circ}\right)_{11} T\left(90^{\circ}\right)_{226} \\
& =-2(2-\sqrt{2})
\end{aligned}
$$

Now calculate the needed ratios of the $T_{i j 6}$ to the $T_{116}$ aberration:

$$
\begin{aligned}
& \frac{T\left(360^{\circ}\right)_{126}}{T\left(360^{\circ}\right)_{116}}=-\frac{L}{8}(2 \sqrt{2}-1) \\
& \frac{T\left(360^{\circ}\right)_{216}}{T\left(360^{\circ}\right)_{116}}=-\frac{2}{L} \\
& \frac{T\left(360^{\circ}\right)_{226}}{T\left(360^{\circ}\right)_{116}}=-1
\end{aligned}
$$

\subsection{Making Sense of It All}

This is not very enlightening.

Without calculation, we can determine the sign of all the aberrations. First, it is obvious that all the aberrations of the $90^{\circ}$ cell are positive. Second, if we require that the $360^{\circ}$ sector have more than three cells (which is necessary in order that the geometric aberrations cancel), then $\alpha<0, \gamma>0, \beta>0$, and $\mu^{\prime}<0$.

Table 2 shows the sign of the ratios of the actual and needed aberrations.

So what? Note the following:

1. It is possible to make the $360^{\circ}$ sector achromatic.

2. Because of this, the listed aberrations are in a constant ratio. 
The conclusion is that there is nothing we can do, using only quadrupoles, to cancel the aberrations. We must introduce sextupoles.

The second order terms of the $360^{\circ}$ sector are linear in sextupole strength, i.e,. any aberration my be expressed in the form

$$
T_{i}=Q_{i}+\sum_{j} a_{i j} S_{j}
$$

where $Q$ is value of the aberration with the sextupoles turned off, $S_{j}$ is the $j^{\text {th }}$ sextupole family, and $a_{i j}$ is the contribution of the $j^{t h}$ sextupole family to the $i^{\text {th }}$ aberration.

Furthermore, the ratio $T_{226} / T_{116}=-1$ for both the actual and needed case (if we get the value of $T_{226}$ correct, $T_{116}$ comes with it for free). We are left with three aberrations to adjust. Invoking eq. (14) gives us a system of three equations with three unknowns. Thus, three sextupole families are needed.

\section{Conclusion}

The second-order aberrations in a $360^{\circ}$ sector are linear in sextupole strength and of constant ratio. When a $90^{\circ}$ cell is added to the sector, one can calculate the aberrations needed in the $360^{\circ}$ sector to make this new $450^{\circ}$ beamline achromatic. The ratios of the needed aberrations are not the same as the ratios of the actual aberrations, so sextupoles must be used. Because two of the aberrations are coupled, we are left with three aberrations, which implies the need of three sextupole families.

Constructing the $360^{\circ}$ section from six $60^{\circ}$ cells, and placing pairs of sextupoles $180^{\circ}$ apart, gives the necessary number of families.

\section{Acknowledgments}

The author wishes to thank Dave Carey, who read the initial drafts of this work and provided encouragement. The author also thanks Don Edwards and Helen Edwards, who suggested investigating this optical system. 


\section{A Chromatic Aberration Terms for a Single $90^{\circ}$ Cell}

This continues the calculation of individual terms for a single $90^{\circ}$ cell. the procedure and variables are as defined in Section 2.1. Because all terms are for a $90^{\circ}$ cell, the " $90^{\circ}$ " will be dropped without introducing ambiguity.

A.1 $T_{126}$

$$
\begin{aligned}
T_{126} & =\left(x \mid x_{0}^{\prime} \delta\right) \\
& =\frac{\partial s}{\partial \delta} \\
& =\frac{\partial}{\partial \delta}[\beta \sin (n \mu)] \\
& =\beta^{\prime} \sin (n \mu)+\beta n \mu^{\prime} \cos (n \mu) \\
& =\beta^{\prime} \\
\beta^{\prime} & =\mu^{\prime} \frac{\partial \beta}{\partial \mu} \\
& =\mu^{\prime} \frac{\partial}{\partial \mu}\left[\frac{L}{\sin \mu}\left(1-\frac{1}{2} \sin ^{2}(\mu / 2)\right)\right] \\
& =-\mu^{\prime} L\left[\left(\frac{\cos \mu}{\sin ^{2} \mu}\right)\left(1-\frac{1}{2} \sin ^{2}(\mu / 2)\right)+\frac{\sin (\mu / 2) \cos (\mu / 2)}{2 \sin \mu}\right] \\
T_{126} & =\frac{L}{2}
\end{aligned}
$$

A.2 $T_{116}$

$$
\begin{aligned}
T_{116} & =\left(x \mid x_{0} \delta\right) \\
& =\frac{\partial c}{\partial \delta} \\
& =\frac{\partial}{\partial \delta}[\cos (n \mu)+\alpha \sin (n \mu)] \\
& =-n \mu^{\prime} \sin (n \mu)+\alpha^{\prime} \sin (n \mu)+\alpha n \mu^{\prime} \cos (n \mu) \\
& =-n \mu^{\prime}+\alpha^{\prime} \\
& =-\mu^{\prime}\left[\frac{\cos (\mu / 2)}{\sin (\mu)}+1\right] \\
& =2\left(1+\frac{\sqrt{2}}{2}\right)
\end{aligned}
$$


A.3 $T_{226}$

$$
\begin{aligned}
T_{226} & =\left(x^{\prime} \mid x_{0}^{\prime} \delta\right) \\
& =\frac{\partial s^{\prime}}{\partial \delta} \\
& =\frac{\partial}{\partial \delta}[\cos (n \mu)-\alpha \sin (n \mu)] \\
& =-n \mu^{\prime}-\alpha^{\prime} \\
& =-T_{116}-2 n \mu^{\prime} \\
& =-2\left(1+\frac{\sqrt{2}}{2}\right)+4 \\
& =2\left(1-\frac{\sqrt{2}}{2}\right)
\end{aligned}
$$




\section{B Chromatic Aberration Terms for the $360^{\circ}$ Sector}

This section calculates the individual terms for a $360^{\circ}$ sector. The variables $\alpha, \beta$, and $\gamma$ are the usual Twiss parameters at the end of the first cell. The sector is composed of $n$ identical cells. Because all terms are for a $360^{\circ}$ cell, the " $360^{\circ}$ " label will be dropped without introducing ambiguity.

B.1 $T_{116}$

$$
\begin{aligned}
T_{116} & =\left(x \mid x_{0} \delta\right) \\
& =\frac{\partial c}{\partial \delta} \\
& =\frac{\partial}{\partial \delta}[\cos (n \mu)+\alpha \sin (n \mu)] \\
& =-n \mu^{\prime} \sin (n \mu)+\alpha^{\prime} \sin (n \mu)+\alpha n \mu^{\prime} \cos (n \mu) \\
& =\alpha n \mu^{\prime}
\end{aligned}
$$

B.2 $T_{126}$

$$
\begin{aligned}
T_{126} & =\left(x \mid x_{0}^{\prime} \delta\right) \\
& =\frac{\partial s^{\prime}}{\partial \delta} \\
& =-\frac{\partial}{\partial \delta}[\beta \sin (n \mu)] \\
& =\beta^{\prime} \sin (n \mu)+\beta n \mu^{\prime} \cos (n \mu) \\
& =\beta n \mu^{\prime}
\end{aligned}
$$

B.3 $T_{216}$

$$
\begin{aligned}
T_{216} & =\left(x^{\prime} \mid x_{0} \delta\right) \\
& =\frac{\partial c^{\prime}}{\partial \delta} \\
& =-\frac{\partial}{\partial \delta}[\gamma \sin (n \mu)] \\
& =-\gamma^{\prime} \sin (n \mu)-\gamma n \mu^{\prime} \cos (n \mu) \\
& =-\gamma n \mu^{\prime}
\end{aligned}
$$


B.4 $T_{226}$

$$
\begin{aligned}
T_{226} & =\left(x^{\prime} \mid x_{0}^{\prime} \delta\right) \\
& =\frac{\partial s^{\prime}}{\partial \delta} \\
& =\frac{\partial}{\partial \delta}[\cos (n \mu)-\alpha \sin (n \mu)] \\
& =-\alpha n \mu^{\prime} \\
& =-T_{116}
\end{aligned}
$$

